(C) 1994-2008 IEEE. Personal use of this material is permitted. However, permission to reprint/republish this material for advertising or promotional purposes or for creating new collective works for resale or redistribution to servers or lists, or to reuse any copyrighted component of this work in other works must be obtained from the IEEE.

\title{
Teaching Design Through Design Competition
}

\author{
Wayne T. Padgett \\ Rose-Hulman Institute of Technology \\ Terre Haute, IN 47803-3999
}

\begin{abstract}
The use of competition both inside and outside the classroom, but particularly the use of an external design competition is examined. Although there are a number of difficulties in integrating this type of experience into a curriculum, design competitions remain an extremely motivational and useful tool in the hands of engineering faculty members. This paper details some of the benefits and difficulties associated with various design competitions and experiments with in-class competition.
\end{abstract}

\section{Introduction}

Thirty years ago, "the design process" was something you learned by experience or apprenticeship, not in a course or from a book. Today, the design process has become a part of the curriculum, both as an integral part of various courses and in whole courses intended to emphasize a particular technique for managing creativity in design. Part of the reason for the emphasis on teaching design is because students get a more uniform exposure to best processes in a classroom than they would by experience, since some would work with peers who follow careful design procedures and others would work with much less careful peers. Another reason is because of a change in the pre-college experience of the typical student. In the recent past, many students came to engineering schools with significant experience in building simple projects and in disassembling and repairing simple appliances. Today, however, students come to engineering schools with much less of this kind of experience than they did just a few years ago.

As a result, very few of today's students have already experienced the thrill of "getting it to work." Their lack of experience leads to two related problems: they tend to be very hungry for practical applications in the classroom, and they lack the intuition built through experience. Without the experiential base to tie concepts to, they have difficulty holding on through the "dry" or theoretical parts of the material, and without the knowledge gained from experimentation, design seems more like guessing than choosing. Design education helps to resolve both of these issues, and as students come to us with less experience, design education becomes more important than ever.

An informal survey of the students in my classes has confirmed that they are strongly interested in the practical applications of the material that I present to them. In fact, when questioned about their goals for the course, they will normally volunteer the goal of learning about practical applications of the material. At first, I was surprised by the consistency of this goal across various courses, but this appears to be something that is common to almost every engineering discipline.

Design problems tend to be challenging and motivational, helping to satisfy both the goal of the students for practical material, and the goal of the faculty for instruction in design processes. Because design projects work best when they are open ended and long term, they compete heavily with the conceptual material. In every course the instructor must choose some balance between practical and conceptual material, usually with pressure from students for the practical, and pressure from faculty teaching following courses for the conceptual. I have heard a variety of theories about how to handle this tradeoff from my colleagues, but I think there is a consensus that the students would generally choose more of the practical and design oriented material and not enough of the conceptual material.

In an ideal world, all of the material would be presented in such a motivational way that students would walk away from each lecture looking for an opportunity to apply the material and essentially create their own labs. Unfortunately, I've only been to a few such lectures and have given fewer. Until it is possible to get the repeatable results from people that we get from physical processes, such a goal is unlikely to be achievable. On the other hand, a number of methods for giving students exposure to practical design experience are available.

\section{Capstone design courses}

Students have academic opportunities to gain practical experience in their discipline in labs, end-of-course projects, project courses, and capstone design experiences. Each of these types of experience has its advantages and disadvantages in giving students opportunities to apply the material from their coursework and get an introduction to making the choices a designer must make. Labs are great for applying just a few simple concepts, and can occasionally be structured in a relatively open way that gives students the flexibility to really experiment. Normally, however, labs are too short to achieve much in the way of design education. End-ofcourse projects and single term project courses can offer substantial opportunities to apply other coursework, but 
still don't leave enough time to allow a complete design cycle. Ideally, a design project would give the students time to brainstorm, evaluate alternatives, do a detailed design, build and test a prototype, and then iterate and document their design. This complete cycle is difficult to perform in a course other than a multi-term capstone design course.

Not only does a multi-term design course make a good vehicle for teaching a complete design cycle, but the longer experience allows for more challenging and complete projects that are inherently more satisfying to the student's desire for practical application. Are there any drawbacks to the capstone design course? Of course. Capstone design courses get their name because they tend to come at the end of the curriculum, essentially waiting until the end before anything "real" happens, at least in the student's eyes. This is obviously done because it allows the students to take maximum advantage of their coursework in the project, but it also tends to reserve most of the motivational benefits for the very end of the educational process. This results in a sort of "save the dessert for last" philosophy. In addition, capstone design courses tend to make it difficult to incorporate interdisciplinary projects involving students from several majors. Either a group of departments must cooperatively manage the projects, or a department must find ways to motivate non-majors to participate in its projects. Either method requires tremendous flexibility and effort to be successful.

\section{Design competitions}

There is an alternative method for emphasizing design and accomplishing student motivation which does not normally take the form of an academic course. Use of student design competitions can be an excellent way to accomplish these goals with few of the drawbacks mentioned above. In addition, student design competitions have a number of distinct advantages.

First, whether the competition is internal to the school, or a national or international competition, the difficulty of the problem and the lure of competition tend to be extremely motivational for the students involved. The pleasure of seeing students excel can even be motivational for faculty.

Second, there is no direct pressure on the students involved. Unlike an academic course, participation is voluntary and there is no grade at the end.

Third, the types of projects can easily be and often must be multidisciplinary, so that students of various majors can be involved, often not in their own specialization. Since the project group need not be associated with a particular department, there are fewer bureaucratic obstacles.
Fourth, students can participate in various ways at various levels of their academic career. Although freshmen and sophomores may not usually take technical leadership positions in a competitive design team, they can perform all kinds of administrative tasks, from organizational to fund raising, and they can be involved in much of the time-consuming fabrication processes.

Fifth, and finally, a design competition effort meets many of the educational objectives that faculty nationwide are striving to include in academic curricula. Students are required to participate in the complete design cycle on projects that can last all year and iterate from previous year designs. Team skills and scheduling, planning, and budget skills are required, as are well developed communications skills for various public relations and fund raising events. The students also generally learn a great deal on their own in the process of solving problems, going beyond classroom materials and developing the skills for lifelong learning.

Are there disadvantages to using a design competition for motivating and educating students? Of course. These include the difficulties of assigning academic credit for the work, the fact that not all students participate, the potential for students to work on the competition at the expense of their academic coursework, and the effort required to guide and support a successful team.

\section{Comparison}

Given the fact that not every student will voluntarily participate in a design competition effort, how can we make use of the opportunity to improve the educational process for students who want to be involved? Forcing students to be involved in external competitions seems very unlikely to achieve the desired result. The other extreme would be to give no academic credit for participation in any form. Amazingly, design competitions can be so motivational that it is possible to maintain a team even without any academic credit at all. However, since participation in a design competition has so many educational benefits, it only seems reasonable to encourage students to get involved, and to give some kind of credit for their effort.

Ideally, there could be some type of compromise between the two, allowing some credit for supervised, graded work and perhaps reducing some of the double load for students who are active in a design competition and also required to participate in a capstone design course. One convenient compromise is to take subsets of the design competition's problem and use them for project courses and capstone projects. This puts the design competition group in the position of a project "client" with other students rendering services under the supervision of a faculty member. Care must be taken to 
avoid conflicts of interest such as when a member of the design competition team becomes responsible for specifying their own "services."

Clearly, design courses have their own merits which are not easily duplicated in a voluntary design competition. These include such benefits as rigorous requirements for use of a specific design process, scheduling methods, and documentation, and of course, individual accountability for effort. Although these kinds of characteristics can be encouraged, and are necessary for success in a design competition team, it is impossible to impose them on a voluntary group.

On the other hand, it is possible to reap some of the benefits of competition in regular coursework and design projects. Internal design competitions can be quite effective in arousing interest and often generate quite creative results. Internal competitions seem to be limited by the tradeoff between the difficulty of the problem limiting the number of people willing to put in the effort, and the simplicity of the problem limiting the number of people interested enough to participate.

If a design problem is specific enough, it may be appropriate for use as part of a course, and a competitive element may be included. Rather than awarding bonus points or an improved grade, however, it has been my experience that the response is better for simple short term awards like a small monetary award or even a candy bar. Grade awards tend to just inflate a good student's already good grade. Use of a monetary award may seem a bit cynical, since students are actually paying to learn already, but since students treat the cash as a windfall, and the award need not be large (just five dollars works well) there doesn't seem to be any harm in using cash prizes if it is done sparingly. The students seem to enjoy a little short term reward for their effort, and usually even those who aren't likely to win often enjoy the game of competing more than they would just working an assignment.

Clearly, there is a danger here of getting students into a frame of mind that assignments aren't worth doing if there's no short term reward. While this remains a possibility in the extreme, a little sound judgment and limited resources make it unlikely that use of rewards will get out of hand. Since the effects can be so beneficial, it seems reasonable to allow judicious use of competition and awards in cases where it is appropriate.

\section{Competition as motivation}

Using competition and small cash awards has been an ongoing experiment in the digital signal processing lab course at Rose-Hulman. During the quarter the students participate in a variety of labs involving real-time signal processing techniques and study various applications such as speech processing. For the final lab of the quarter a little extra excitement is injected by giving the students speech files which have been corrupted in various ways. The speech files contain clues as to where on campus to find a five dollar bill. The first group to decode a clue and retrieve the bill gets to keep the money.

This is a fine example of the use of competition and an award to build a little excitement into a lab activity, and credit is due to K.E. Hoover for the idea and some of the financing of the awards. While this isn't a design activity, the lab does promote creativity and problem solving for the students. On a number of occasions, students have demodulated fairly complicated signals to the point of intelligibility using methods substantially different from a classical demodulation scheme. On one occasion, a pair of students came up with an alternative approach (simply searching for the bills) which was quite effective and resulted in the use of coupons instead of real bills this year. The real testimony to the effectiveness of the competition though, is the fact that at 4:45 p.m. on the last day of classes, there were still two unsolved clues, and all the lab groups were still working, even though they were not required to solve all the clues to get credit for the lab.

\section{The Rose-Hulman Aerial Robotics Club}

Another example of the effectiveness of design competitions is the success of the various design clubs on Rose-Hulman's campus. There are teams competing in the International Aerial Robotics Competition, the Sunrayce (Solar Car), the Human Powered Submarine Race, and the Society of Automotive Engineers Formula Race. As the faculty advisor for the Aerial Robotics club, I can attest to the unique educational and motivational benefits of the design competition for club members.

The mission for the competition is to build and fly a fully autonomous vehicle which can map a simulated hazardous waste dump, by locating and identifying labeled barrels, and by retrieving a sample disk from one of the barrels. The club is using an RC model helicopter outfitted with inertial navigation sensors, a differential GPS unit, and an onboard 486DX100 computer, all in communication with a ground computer which processes the images from an onboard CCD camera.

It is truly amazing to see the level of effort put forth by students who may or may not excel in the classroom. The beauty is that the students are giving this kind of effort to essentially educate themselves. Add to this the fact that two sophomores, Friso Schlottau (Applied Optics), and Jeremy Conner (Chemical Eng.) are leading the club composed of freshmen to graduate students with a variety of majors, and you have a nearly ideal educational situation. Students from a variety of 
disciplines, motivated to learn for themselves, working together to accomplish a very challenging goal. All of the latest educational methods are incorporated: cooperative learning, life-long learning skills, problembased education, and teaming skills. With help from myself and other interested faculty members, the team members are learning where to go to learn the material they need on a just-in-time basis. When they build a design that doesn't work, they must test it and redesign it themselves. If they don't succeed this year, they have next year's competition to work toward.

The Rose-Hulman Aerial Robotics Club is in its second full year of operation and will be taking a vehicle to the competition for the first time in July 1997. Good support from the school, corporate donors and the Student Government Association has made it possible for the team to build a capable vehicle with much of the final development work to be done this Summer by students voluntarily staying on campus after school is over.

The club has generated several academic projects for which students received credit, many of whom were not directly involved in the club. A partial list of these projects includes a Integrated Freshman Year Curriculum project simulating the search for barrels, a Senior Project for a group of four Electrical Engineering majors who designed and built a sonar altimeter with serial interface for the vehicle, a Freshman Design Project in Mechanical Engineering in which forces on the vehicle test stand were simulated, a Satellite Communications course project evaluating the GPS equipment accuracy, and several other imaging and controls projects in the Electrical and Computer Engineering Department. Several projects are anticipated next year in the Mechanical Engineering Department relating to optimizing the engine and helicopter payload performance.

\section{Conclusions}

Design competition teams can't replace the capstone design course because of the need for structure and accountability in the curriculum. However, design competition teams can contribute substantially to the educational experience for engineers. The availability of a design competition team gives students a source for real projects where their results will be put into practice. A design competition gives younger students a chance to "taste the dessert first" while they work their way through the demands of the curriculum, and likely improves retention. Finally, the operation of a design competition team simulates the workplace in ways no course can, putting students up against the best other schools can offer, and making teamwork and organizational skill not just important, but critical. As you consider ways to improve your curriculum, consider sponsoring a design competition team - it's quite rewarding.

\section{References}

[1] Aerial Robotics Club: http://www.rose-hulman.edu/Users/groups/ ARC/Public/HTML/index.html

[2] Solar Phantom:

http://www.rose-hulman.edu/Users/groups/ SolarPhantom/HTML/index.html

[3] Human Powered Sub:

http://www.rose-hulman.edu/Users/groups/ ScubaClub/Public/HTML/index.htm

[4] Team Rose Motorsports:

http://www.rose-hulman.edu/Users/groups/

TeamRose/HTML/index.html 